\title{
The Application and Research of Teaching Mode of Sports Club
}

\author{
Fanwei Meng \\ Changchun University of Science and Technology, Changchun 130000, China \\ 13742883@qq.com
}

\begin{abstract}
Keywords: Sports Club, Teaching Mode.
\end{abstract}
\begin{abstract}
At present, with the change of education alphilosophy,inorder to improve the effectof physical education, the major universities are constantly changing teaching mode.Sports club is a new teaching mode, whose purposeis to develop students' practical ability. It changes the boring and low efficient traditional teaching mode, to promote students' interest in sports and improve the quality of sports. In order to improve the teaching effect of sports clubs, teachers need to combine the actual situation of students and carry ou treasonnable reform.
\end{abstract}

\section{Introduction}

In order to better promote the effect of sports teaching in colleges and universities, some universities to develop the sports club teaching mode. College teachers should realize the teaching mode of sports club type, understand its connotation and meaning, to realize the present stage our country club type teaching problems, combined with the characteristics of high students in China and the status quo of the teaching resources, reasonable reform, in order to promote the development of sports teaching.

\section{The connotation and features of sports clubs}

Sports club teaching is a new teaching mode, is in the student-centered teaching concept formed under the influence. Under this kind of teaching form, students can according to their own interests, the combination of school teaching conditions, choosing the content of the study has a certain spontaneity. And in the sports teaching club, students can according to their own interest, system of learning the knowledge and skills of different sports, through independent learning better master sports skills, cultivating their consciousness of physical exercise, form the consciousness of lifelong physical exercise. At present, the colleges and universities in our country, the sports club teaching mode consists of extracurricular sports clubs and sports clubs, class and class inside and outside forms combined sports club. The in-class sports clubs based on the classroom teaching of teaching. Extracurricular sports club is outside of the physical education, physical education teaching activities, to improve the effect of physical education teaching, to better develop the students' interest in sports and exercise habits. And the combination of inside and outside class sports club is under the influence of the concept of lifetime sports, in order to fully develop the students' comprehensive quality, put forward on the integration of sports teaching in classroom extracurricular patterns. Teachers, on the basis of considering the students' individual characteristics, can choose a different course form, reasonable arrangement. To achieve to enhance the students' interest in physical exercise, physical exercise training students' lifelong sports awareness and good habits.

The characteristics of the sports club teaching mode mainly include the following: first, the teaching content more rich. Compared with the traditional teaching mode, can according to the school sports club teaching situation, provide students with basketball, soccer, tennis, badminton and table tennis, swimming and so on traditional sports, can also provide students with cannot be carried out in school sports, such as mountain climbing, rock climbing, swimming, shooting sports, make students carry on the reasonable choice according to their own interest. To a certain extent, expanded the sports learning and exercise content, enriching the content of student's physical exercise, can rise to stimulate students' interest in sport, the role of promoting students' all-round development of body and mind. Second, it is 
easier to inspire the enthusiasm of students to exercise. In the club type teaching mode, the students according to their own interests for the selection of the project activity. Under the guidance of interest, the students' learning and exercise more proactive, promote students' exercise habits. Once again, and students to achieve the goal of exercise. Under the guidance of club teaching forms, students choose according to their interest in sports, to a certain degree of exercise every day, in the common learning environment, a gradual increase in exercise intensity and volume, is beneficial to the exercise reaches a certain level, and encouraged by the results, and harder to achieve higher exercise results improve effect, achieve the goal of the exercise.

\section{The meaning of sports club type teaching}

\subsection{Is helpful to improve students' practical abilities}

The traditional teaching model, students were forced to accept teachers choose teaching content. While students due to their own interests, it is difficult to achieve interest unity. Students are usually interested in not learning enthusiasm is not high, the sports curriculum knowledge will appeal to some students, student sports knowledge and skills to improve co., LTD. And new model of sports teaching provides students with personalized development space, starting from the interests of individual students, arrangement of teaching activities, to the improvement of students' physical education learning enthusiasm and initiative has a good role in promoting, more conducive to students' physical exercise habits, stimulate their movement potential, so that the students can better exercise their practice Force.

\subsection{To promote the improvement of students' interpersonal communication ability}

In the sports club teaching model, students can choose courses according to their interests and independent of time, including the class teacher, curriculum project and time in the class. Have greater degree of autonomy in the teaching mode, can be different professional, different grade students for a free combination, forming different sports interest groups, to a certain extent, increased the different major and grade students the opportunity to communicate to know each other, and make students have the opportunity to better interpersonal communication. And the club type teaching form, increase the interactions between teachers and students, in the form of cooperation on physical education teaching, through different forms of interaction, students also improve their ability to communicate.

\subsection{Promote the integrated development of physical education teaching}

At present, many colleges and universities sports teaching in China focuses on classroom teaching, physical education is effective, lead to the students' practice is limited, can not reach the purpose of enhancing the students physical quality. And the club type teaching mode, can realize integration of physical education class, extracurricular activities. The colleges and universities better extends to the extracurricular physical education teaching activities, make the students according to their own situation and interests reasonable selection exercise program, and promote the students' classroom learning and the effective combination of extracurricular activities.

\subsection{The excavation of the student movement potential}

Sports club teaching model, so that the students can be in different time, space and resources, according to the actual situation to carry on the reasonable choice, exercise to satisfy their own interests and needs, specialty of exercise. By choosing the right sports project and carry on the reasonable training under the guidance of professional teachers, finally causes the student to develop its potential movement can, the technical level of the sport is well improved. Therefore, the use of this teaching mode is good for students' potential, good training results.

\subsection{To promote the construction of campus culture}

Sports club is a new type of campus sports culture activities, due to its highly humanized advantages, gradually accepted by colleges and universities. As the new sports teaching pattern of the evolving, sports clubs in many colleges and universities are known as the focus of the campus culture. In lead students to exercise at the same time, the club's activities that the sports consciousness of college campus. And by the club to student organizations and activities, to improve the enthusiasm of students 
to participate in sports activities by, the development of campus sports culture. Therefore, sports club enriched the campus sports culture connotation, help to build up the positive campus cultural atmosphere.

\section{The problems existing in the teaching of college sports clubs in China at present stage}

\subsection{The students lack consciousness of subjectivity teaching}

Due to the influence of the traditional teaching habits, although many colleges and universities launched a sports club sports teaching, according to the students' interest in teaching activities. However, the new teaching activity of teachers for this connotation understanding is not deep.

In the teaching activities, teachers still stick to the subject status of the teaching activities, do not pay attention to the student individuality development. Show the course choice is narrow, the fixed time, fixed, teachers also causes students options are limited. On the other hand, although the school has carried out many sports elective course of the door, but each course is used in the past. Teaching form, the student or a passive listening, carried out in accordance with the physical task assigned by the teacher physical training, causes students subjective initiative of learning is limited, enthusiasm is not high, is not conducive to students to develop good physical quality.

\subsection{In-class teaching and extracurricular physical exercise is difficult to unity}

In the mode of sports club to colleges and universities in our country at present stage despite the organization form of extra-curricular activities, but the physical education teaching is to classes of physical education teaching mode. But there are a lot of students by their own hobby, different reasons, such as physical quality level of choice is different in the form of sports activities. For sports enthusiasts may choose some extracurricular exercise, but for the class teachers rarely according to students' physical education teaching activities within oneself circumstance reasonable exercise plan, show is the content of the course, method and means basically as a model. This results in a physical education learning in the class and extracurricular exercise is difficult to achieve unity, limited the development of the sports ability of students.

\subsection{Management system is not perfect}

Due to the development of the sports club in colleges and universities in our country late, leading to the school for its management is not form a unified model. At present, although a lot of colleges and universities have established a lot of PE teaching club, but most of the club implementation effect is not ideal. Many club teaching organizational structure appears to be larger, but internal management problem is bigger, activities organizing and planning was flawed, lead to restrict its development. Therefore, the school should be clear to the intramural sports club system specification, unified club learning evaluation standard, to strengthen the internal management of the sports club to promote its healthy development.

\subsection{Teachers and equipment resources co., LTD}

With enrollment expansion of colleges and universities in recent years, the number of students is increasing. At the same time, the sports club is based on students' interests and needs, the number of cases club students more may need some more accordingly. The physical education teachers in colleges and universities is limited, physical training equipment and limited space. In school sports club exercise quality due to the limitation of time and place is not ideal. Therefore, in order to better promote the development of sports clubs, schools should pay attention to strengthen the construction of teachers and equipment.

\section{Strategies to promote the development of sports club type teaching mode}

\subsection{Establish a predominantly student club teaching mode}

Predominantly student sports club teaching form can better promote the improvement of students' physical quality. Teachers should realize the necessity of teaching idea transformation, organizations to make the new teaching idea of students, teachers encourage teachers change the teaching idea, according to the actual situation, change teaching atmosphere, more give students interactive teaching 
classroom. Using the encouraging language, according to students' learning level and psychological characteristics, respect students' interests and needs, organization of teaching activities. Enliven the teaching organization form, make the teaching activities more flexible, students choose course content, time and classroom teachers, meet the needs of students' different learning and exercise.

\subsection{Specification of sports organization and management of the club}

Want to promote the development of the sports club teaching effects, reasonable management of organization is necessary. First of all, the school should formulate a unified management model, each club under the guidance of management model to establish a clear function division, strict management system of organization's activities. Not only that, in order to promote the development of sports clubs, schools should also give full play to the function of its management and supervision, equipment purchase, to raise funds for sports clubs such as reasonable management and supervise and guide all work. Guide them according to the characteristics of the different projects, the establishment of scientific and reasonable teaching plan, specification within the club management, ensure the activities of scientific and orderly.

\subsection{Establish integration inside and outside the class teaching mode}

In order to improve the students' physical quality, promote the integration of sports club teaching mode of development is necessary. Therefore, schools should be aimed at promoting students' physical quality target, under the condition of students' choose a different club, according to the characteristics of different students, for individual sports teaching design, combine classroom teaching and extracurricular exercise, fully promote students' ability to exercise High.

\subsection{To strengthen the construction of teaching staff}

For different sports club teaching, sports teachers' professional quality is the key to improve the teaching effect. Therefore, in order to guarantee the effect of club sports teaching, the school should pay attention to the construction of sports teachers, actively introduce professional teachers, and systematic training of physical education teachers, comprehensive improve the comprehensive ability of teachers, promote the improvement of teaching effect. And, to understand the situation of the teachers, to encourage timely, arouse teachers' teaching enthusiasm, better promote the development of teaching activities.

\section{References}

[1] Zhang Chuan. Researching the construction of applied undergraduate colleges and universities sports club teaching model [J]. Journal of Shaanxi province education (higher education), 2017. (01): $50+52$.

[2] Interface. To explore the teaching mode of college sports clubs in China [J]. Journal of contemporary sports science and technology, 2016, (35): 80-81.

[3] Kong Jigong. Sports club teaching mode of application and research [J]. Journal of Sichuan vocational and technical college, 2016, (5): 155-157.

[4] Hao Long. Heilongjiang university badminton club development present situation and countermeasure research [D]. Harbin normal university, 2016.

[5] Xiao-hu Chen. College sports club management mode analysis [J]. Journal of contemporary sports science and technology, 2015, (31): 181-182.

[6] Li lei, Linda. Based on the applied undergraduate colleges and universities sports teaching mode of study [J]. Journal of Kunming institute, 2015, (3): 126-128 + 132. Stop.

[7] Field amplitude analysis sports club teaching mode in higher vocational college sports teaching the application [J]. Journal of sport, 2015, (8): 106-107 